\title{
The use of radioiodine in the management of benign thyroid disease
}

\author{
Tony Weetman on behalf of the Working Party of the Royal College of Physicians
}

Tony Weetman MD DSc FRCP, Dean,

School of Medicine and Biomedical

Sciences, University

of Sheffield

Clin Med $2007 ; 7: 214-5$
June 2007 sees the publication of revised Royal College of Physician's guidelines on the use of radioactive iodine in hyperthyroidism. The original guidelines, produced in 1995 by a College Working Party, represented the bodies involved in the administration of radioiodine $\left({ }^{131} \mathrm{I}\right) .{ }^{1}$ The need for these guidelines emerged from the outcome of a survey, reported in this Journal, which showed considerable variation within the UK in the doses of radioiodine used to treat hyperthyroidism, ranging from almost homeopathic through to doses sufficiently large to cause concern over unnecessary use of radiation. ${ }^{2}$ The original guidelines had a major impact on the way radioiodine is given, leading to more uniformity and far better information provision for patients, including formalisation of the necessity for informed consent.

All guidelines require revision to ensure that they remain contemporary and since 1995 the practice has moved on, with the expectation that evidence is clearly assessed and recommendations are made according to well-established criteria. Unfortunately much of the practice with regard to radioiodine has been based on local protocols which have developed since the first use of this treatment in the 1940s. Controlled trials will never be performed in many areas of radioiodine treatment, but the last decade has seen the publication of a number of controlled trials addressing aspects which have remained controversial, and these new data can be used to produce contemporary grading with regard to the level of evidence supporting any recommendation.

\section{Recent developments}

I chaired the Working Party which has tackled the revision, under the impression that this would be a straightforward task encompassing primarily the grading of evidence just mentioned and legislative changes that have imposed even greater stringency on how radioisotopes are used medically. It soon became clear, however, that, as well as the difficulties of finding the necessary proof to grade the evidence supporting existing recommendations, much had changed in the field. Perhaps the biggest development has been the increasing use of radioactive iodine for the treatment of goitre. ${ }^{3}$ Until recently, the only two options for dealing with an unsightly or symptomatic goitre have been levothyroxine treatment, given in sufficient doses to suppress the thyroid stimulating hormone (TSH) (with consequent risks of osteopenia and atrial fibrillation) or surgery. Levothyroxine therapy has a success rate of only $30-60 \%$, depending on goitre size, and non-toxic goitre recurs in 15-40\% of patients after surgery. By contrast, radioiodine treatment in non-toxic goitre can achieve a reduction in the size of the thyroid of around 50\%, and further reduction can occur with a second dose. Apart from hypothyroidism, complications appear minimal although the risks of any subsequent extrathyroidal malignancy remain unknown. Given the increasing enthusiasm for this treatment, particularly when used with recombinant TSH to increase radioiodine uptake and thus minimise radiation dosage, the Working Party felt that we should include this area within the guidelines, which have therefore been retitled to encompass the management of benign thyroid disease rather than hyperthyroidism alone.

Among other developments, the Working Party has considered the evidence that radioactive iodine may worsen thyroid-associated ophthalmopathy, particularly found in smokers, as well as strategies which can be used to minimise this complication. ${ }^{5}$ Although still controversial, there are prospective controlled trial data to show an adverse effect of radioiodine on ophthalmopathy. On the other hand there are currently no controlled trial data on whether radioactive treatment is indicated in subclinical hyperthyroidism (that is, those patients who have a suppressed TSH but normal serum free 
triodothyronine (T3) and thyroxine (T4) concentrations), despite the frequency with which this condition is now being uncovered with the increased use of thyroid function tests in a general population. Recent North American guidelines have indicated that treatment should be considered in subclinical hyperthyroidism, particularly in those over the age of 60 , in those who have heart disease or evidence of increased bone loss, or in those who have symptoms suggestive of thyrotoxicosis. ${ }^{4}$ An important trial led by Simon Pearce in Newcastle upon Tyne is about to start which will examine this question in detail but until the results of this and other trials are available, the Working Party has had to make recommendations for radioiodine usage based on the meagre evidence available.

A further area of contention has been the effect of antithyroid drugs on the outcome after radioiodine. These drugs are often given with the hope of avoiding the rare complication of thyroid crisis (or storm) but this tends to be something done by local custom and practice. Nevertheless, we now have clear evidence that propylthiouracil in particular has a radioprotective action which can reduce the effectiveness of radioactive iodine, even if this drug is stopped several weeks before radioactive iodine is administered. On the other hand, carbimazole appears to have no radioprotective effect provided it is withdrawn shortly before radioactive iodine administration.

Of course, the new guidelines have covered the UK legislative requirements for the administration of radioactive iodine, and I am particularly grateful to the many bodies that have provided advice to ensure that these areas and others have been dealt with as accurately as possible. We have simplified the range of ${ }^{131} \mathrm{I}$ activities which might be prescribed for different thyroid conditions, and provided new information on the radiation protection issues which arise after the administration of radioiodine. Equally important is the information given to the patient after treatment, and we have made recommendations that this information should be accompanied by a portable card with details of treatment date and dose. This is necessary for six months after treatment in the case of travel, during which time sufficient radioactivity may be retained by the patient to trigger security alarms at airports and other facilities. ${ }^{6}$

Since hyperthyroidism and non-toxic goitre are such common conditions, all physicians are likely to come into contact with patients who need, or have had, radioactive iodine. On behalf of the Working Party, I hope that the revised guidelines will be of use to them as well as to endocrinologists and nuclear medicine specialists who are directly involved in the administration of radioactive iodine.

\section{Members of the Working Party}

Mary Armitage, Clinical Vice President, Royal College of Physicians of London; Consultant in Endocrinology, Royal Bournemouth Hospital; Sue Clarke, Joint Specialty Committee on Nuclear Medicine; Consultant Nuclear Medicine Physician, Guy's Hospital; John Frank, British Nuclear Medicine Society; Consultant Nuclear Medicine Physician, Charing Cross Hospital; Jayne Franklyn, British Thyroid Association; Professor of Medicine, University of Birmingham; Peter Lapsley, Patient and Carer Network, Royal College of Physicians of London; John Lazarus, British
Thyroid Association; Professor of Clinical Endocrinology, Cardiff University; Val Lewington, Joint Specialty Committee on Nuclear Medicine; Consultant Nuclear Medicine Physician, Royal Marsden Hospital; Susan Owens, Institute of Physics and Engineering in Medicine; Consultant Clinical Scientist, Christie Hospital, Manchester; Tony Weetman (Chair), British Thyroid Association; Dean, School of Medicine and Biomedical Sciences, University of Sheffield.

\section{References}

1 Lazarus JH. Guidelines for the use of radioiodine in the management of hyperthyroidism: a summary. Prepared by the Radioiodine Audit Subcommittee of the Royal College of Physicians Committee on Diabetes and Endocrinology, and the Research Unit of the Royal College of Physicians. J R Coll Physicians Lond 1995;29:464-9.

2 Hedley AJ, Lazarus J, McGhee SM et al. Treatment of hyperthyroidism by radioiodine. Summary of a UK national survey prepared for the Royal College of Physicians Committee on Endocrinology and Diabetes. J R Coll Physicians Lond 1992;26:348-51.

3 Hegedus L, Bonnema SJ, Bennedbaek FN. Management of simple nodular goiter: current status and future perspectives. Endocr Rev 2003;24:102-32.

4 Surks MI, Ortiz E, Daniels GH et al. Subclinical thyroid disease: scientific review and guidelines for diagnosis and management. JAMA 2004;291:228-38.

5 Bartalena L, Marcocci C, Tanda ML et al. Cigarette smoking and treatment outcomes in Graves ophthalmopathy. Ann Intern Med 1998;129:632-35.

6 Gangopadhyay KK, Sundram F, De P. Triggering radiation alarms after radioiodine treatment. BMJ 2006;333:293-4. 